\title{
Health-resource use and costs associated with fibromyalgia in France, Germany, and the United States
}

This article was published in the following Dove Press journal:

Clinico Economics and Outcomes Research

22 April 2013

Number of times this article has been viewed

Tyler Knight'

Caroline Schaefer'

Arthi Chandran ${ }^{2}$

Gergana Zlateva ${ }^{2}$

Andreas Winkelmann ${ }^{3}$

Serge Perrot ${ }^{4}$

'Health Economics and Outcomes Research, Covance Market Access Services, Gaithersburg, MD, USA; ${ }^{2}$ Primary Care Health Economics and Outcomes Research, Pfizer Global Health Economics, New York, NY, USA; ${ }^{3}$ Department of Physical Medicine and Rehabilitation, University Hospital Munich, Munich, Germany; ${ }^{4}$ Service de Médecine Interne et Thérapeutique, Université Paris Descartes, Paris, France
Correspondence: Tyler Knight Health Economics and Outcomes Research, Covance Market Access Services, 980I Washingtonian Boulevard, 9th floor, Gaithersburg, MD 20878, USA

Tel +l 2406323334

Fax +l 2406323335

Email tyler.knight@covance.com
Background: Fibromyalgia (FM) is a chronic disorder characterized by widespread, persistent pain. Prospective and retrospective studies have demonstrated substantial health-care costs associated with FM in a number of countries. This study evaluated and compared healthresource use (HRU) and associated costs related to FM in routine clinical practice across the US, France, and Germany.

Methods: Two separate, cross-sectional, observational studies of subjects with FM were conducted: one in the US and one in France and Germany. HRU related to prescription medication, physician office visits, diagnostic tests, and hospitalizations was abstracted from chart review; patient out-of-pocket costs and lost productivity were collected via subject self-report. Costs were assigned to HRU based on standard algorithms. Direct and indirect costs were evaluated and compared by simple linear regression.

Results: A total of 442 subjects (203 US, 70 France, 169 Germany) with FM were analyzed. The mean (standard deviation) age in the US, France, and Germany was 47.9 (10.9), 51.2 (9.5), and 49.2 (9.8), respectively $(P=0.085)$. Most subjects were female ( $95 \%$ US, $83 \%$ France, $80 \%$ Germany) $(P<0.001)$. Adjusted annual direct costs per subject for FM were significantly higher in the US (\$7087) than in France (\$481, $P<0.001)$ or Germany $(\$ 2417, P<0.001)$. Adjusted mean annual indirect costs per subject for FM were lower in the US (\$6431) than in France $(\$ 8718)$ or Germany $(\$ 10,001)$, but represented a significant proportion of total costs in all countries.

Conclusion: The significant HRU and costs associated with FM in the US, France, and Germany documented in this study highlight the substantial global economic burden of FM. Indirect costs represented a significant proportion of the total costs, particularly in Europe. Comparisons between the three countries show differences in HRU, with significantly higher direct costs in the US compared with France and Germany.

Keywords: fibromyalgia, cost, burden of illness, United States, France, Germany

\section{Introduction}

Fibromyalgia (FM) is a chronic disorder of unknown etiology, characterized by persistent, widespread pain. ${ }^{1}$ FM is frequently accompanied by a number of other symptoms and comorbid conditions, including depression, anxiety, fatigue, headache, irritable bowel and bladder, and cognitive dysfunction. ${ }^{2-6} \mathrm{FM}$ was estimated to affect $2 \%$ of the general population in the US, ${ }^{6}$ although the true prevalence may be higher, ${ }^{7}$ and up to $6 \%$ of the general population in Europe..$^{8-11}$

A number of studies have evaluated the health-care payer burden and documented the direct costs associated with FM in the US and Europe. Several of these studies have reported that patients with FM are high consumers of health-care services and that 
there are substantial direct health-care costs associated with FM. ${ }^{5,12-18}$ However, very few data on out-of-pocket patient costs have been documented, ${ }^{19}$ with no studies in the US and only a small number in Europe. ${ }^{20,21}$

Studies in the US and Europe have also examined indirect costs associated with FM. FM symptoms, such as pain, fatigue, and sleep disturbance, can lead to substantial limitations in physical functioning and activities of daily living (ADL), ${ }^{19}$ together with lost productivity through higher absenteeism and presenteeism, unemployment, and disability, leading to significant costs. ${ }^{5,12-14,19,22,23}$ The indirect costs documented in these studies have been shown to represent a large proportion of total costs; however, the studies have been inconsistent in the types of indirect costs they include, making comparisons between countries and an understanding of the overall global burden difficult. No studies have examined and compared direct and indirect costs associated with FM in the US with countries in Europe.

This study combines a retrospective chart review with patient-reported data on treatment, out-of-pocket costs, and productivity to more comprehensively measure and compare costs associated with FM across countries and highlight the global burden of FM. In particular, the impact of lost productivity and indirect costs associated with FM is evaluated.

\section{Methods}

\section{Study methodology and subjects}

Two separate cross-sectional, observational studies involving subjects with FM were conducted: one in the US and one in France and Germany. Data from the individual studies have formed part of previously published work, ${ }^{24-29}$ but this is the first time that health-resource use (HRU) and costs in the US, France, and Germany have been compared directly. The studies included subjects with FM recruited from 20 community-based physician offices (eight GPs, six rheumatologists, three neurologists, and three psychiatrists) in the US, 18 community-based physician offices (15 GPs and three rheumatologists) in France, and 15 community-based physician offices (14 GPs and one orthopedist) in Germany. Subjects were required to have a prior diagnosis of FM by a rheumatologist or pain specialist, to have experienced widespread pain (above and below the waist and on both sides of the body) for $\geq 3$ months, and to have experienced pain in the past 24 hours. Subjects were also required to have been in treatment at the enrolling physician's practice for $>3$ months. All subjects were aged between 19 and 65 years in the US study, and $>18$ years in the European study. To enable a direct comparison, only subjects aged
19-65 years from the European study were included in this analysis. As such, the demographic and clinical characteristics of the US subjects are similar to those previously published, ${ }^{24,25}$ whereas those for the European subjects are distinct from previous publications. ${ }^{26-28}$ Subjects were excluded if they had participated in an investigational drug study within 30 days prior to the survey or had a concomitant illness unrelated to FM that was likely to confound the assessment of FM.

The protocol was approved by a central institutional review board in the US (Schulman Associates Institutional Review Board, Cincinnati, OH, USA), and by central and local accredited ethics committees in France and Germany. No medical interventions or invasive procedures were required by the study protocol. All subjects provided written informed consent.

Both studies were conducted in a similar fashion. Site study staff identified potential subjects when they presented for routine visits. After subjects provided written informed consent, they were asked to complete a selfadministered patient questionnaire. Site staff completed a case-report form based on review of the subject's medical records and conducted an assessment of FM using the Manual Tender Point Survey exam. ${ }^{30}$ Data recorded included clinical characteristics, specific pain associated with FM, current and previous medications for FM, and FM-related office visits, diagnostic tests, and hospitalizations. The determination of whether or not a service was FM-related was at the discretion of the investigator, based on guidance provided in the study protocol. Determination of comorbid conditions was made by the clinical investigator. Information collected via the patient questionnaire and case-report form was not associated with a subject's personal identifying information, but was associated with a study-specific identifier assigned at enrollment to allow linking of individual subjects' clinical and survey data in the analysis.

\section{Patient questionnaires}

The patient questionnaire included five validated qualityof-life questionnaires for each country: the EuroQol, ${ }^{31}$ the Medical Outcomes Study Sleep Scale, ${ }^{32}$ the Hospital Anxiety and Depression Scale, ${ }^{33}$ and culturally specific versions of the Fibromyalgia Impact Questionnaire (FIQ), ${ }^{34-36}$ with the Multidimensional Assessment of Fatigue ${ }^{37}$ in the US only and the Modified Brief Pain Inventory Short Form in France and Germany only. ${ }^{38}$ In addition, study-specific questions were developed to assess: treatment satisfaction; perceived treatment effectiveness; out-of-pocket costs associated with 
FM; impact of FM on employment status, productivity, and HRU; average pain over the past 24 hours (US study only); and impact of FM on cognitive function and ADL (US study only). FIQ total scores were used to define FM severity level: $0-<39$ was considered mild, 39-<59 moderate, and 59-100 severe. ${ }^{39}$

\section{Costing}

Quarterly direct costs associated with prescription medications, physician visits, diagnostic tests, hospitalizations, emergency room visits (US study only), and monthly indirect costs (days missed from work or costs of disability due to FM) were assigned retrospectively, based on physicianreported HRU (physician visits, diagnostic tests, prescription medications, emergency room visits, and hospitalizations) and subject-reported lost productivity (work missed and disability costs). Monthly direct subject out-of-pocket costs for medical care and nonmedical-related costs (eg, assistance with ADL) were self-reported. Direct and indirect costs associated with FM were calculated in 2009 US dollars (US study) and 2008 euros (European study) using a societal perspective that incorporates all costs to patients, payers, and society.

In the US study, costing algorithms were developed to assign 2009 unit costs to each unique type of resource utilized. We assigned Medicare payment rates to HRU as a proxy for costs. Unit costs for office visits and office-based procedures or tests were assigned based on the most recent (2009) fiscal year (FY) Medicare Physician Fee Schedule. ${ }^{40}$ Unit costs for emergency room visits not resulting in hospital admission were assigned based on the FY 2009 Medicare Hospital Outpatient Prospective Payment System. ${ }^{41}$ Unit costs for hospitalizations were assigned based on the FY 2009 Medicare Hospital Inpatient Prospective Payment System. ${ }^{42}$ Information on admitting diagnosis, procedures performed, and length of stay were used to map hospitalizations to appropriate diagnosis-related groups. Unit costs for FM medications were assigned based on $80 \%$ of average wholesale price, ${ }^{43}$ as taken from the 2009 ReadyPrice (Thomson Reuters, New York, NY, USA). ${ }^{44}$

For indirect costs, costing algorithms were developed to assign unit costs to subjects' lost productivity (eg, subjectreported time missed from work), based on average wage data. ${ }^{45}$ For subjects employed full- or part-time, average wage rates were assigned to subject-reported days missed from work and to hours of work time lost due to FM. For subjects who were disabled due to FM, average wage rates were applied to the number of lost days of work for that individual from the date they reported being disabled. In the US study, the average monthly disability payment ${ }^{46}$ was also applied to the number of months the subject reported disability due to FM.

In the European study, costing algorithms were developed to assign 2008 unit costs to each unique type of resource utilized. Unit costs assigned to office visits and office-based procedures were based on current physician fee schedules (ie, Classification Commune des Actes Médicaux in France ${ }^{47}$ and Einheitlicher Berwertungsmaßstab in Germany ${ }^{48}$ ). Unit costs assigned to hospitalizations were based on current hospital case-rate payments (ie, Programme de Médicalisation des Systèmes d'Information in France ${ }^{49}$ and German DiagnosisRelated Group in Germany ${ }^{50}$ ). Medication costs were based on private quotes or current drug price lists (ie, Thériaque in France $^{51}$ and Rote Liste in Germany ${ }^{52}$ ). Unit costs assigned to days missed from work and on disability were based on Eurostat wage data.

In order to compare costs between studies, European costs were converted to 2009 US dollars by first multiplying the 2008 euro amount by the 2008 purchasing power parities published by the Organisation for Economic Co-operation and Development (OECD) ${ }^{53}$ for actual individual consumption, and then multiplying direct costs by country-specific general inflation rates and indirect costs by country-specific labor inflation rates.

\section{Statistical analysis}

Summary statistics were calculated, including means, standard deviations (SDs), medians, and ranges for continuous variables and frequency distributions for categorical variables. Unadjusted bivariate comparisons were made by Kruskal-Wallis tests on continuous variables and by Pearson Chi-square tests on categorical variables. Mean direct and indirect costs were estimated from a general linear regression model. The model included the following covariates: country, age, gender, employment status, number of comorbid conditions, time since FM diagnosis, and FIQ severity level (mild, moderate, or severe). Statistical significance was evaluated at the 0.05 level, with no adjustments for multiple comparisons. The data were held and analyzed by Covance. All analyses were performed using PC-SAS version 9.1 (SAS Institute, Cary, NC, USA).

\section{Results and discussion Demographic and clinical characteristics}

A total of 442 subjects (203 US, 70 France, 169 Germany) were included in the analyses. Subjects in the US study were 
on average 2-3 years younger than subjects in the European study; mean (SD) age was 47.9 (10.9) years in the US, 51.2 (9.5) years in France, and 49.2 (9.8) years in Germany $(P=0.085)$ (Table 1). There were a higher proportion of females in the US study (95\% in US vs $83 \%$ in France and $80 \%$ in Germany; $P<0.001)$. Approximately $41 \%$ of US subjects were employed either full- or part-time, compared with $40 \%$ in France and 44\% in Germany. Over one-quarter (27\%) of US subjects were disabled, compared with $11 \%$ in France and only 3\% in Germany. This difference may be related to the higher proportion of patients with severe FM in the US (66\%), as patients with more severe FM are more likely to report being disabled. ${ }^{24}$ It may be that different views on disability in different countries also played some role, but the study did not examine this. A higher proportion of European subjects were retired (24\% in France and 10\% in Germany) compared with US subjects (6\%). OECD data indicate that the effective retirement age for women in France is 59.7 years, compared with 64.8 years in the US and 60.5 years in Germany, which together with the higher mean age of the French subjects may have contributed to the higher proportion of retired subjects in the French sample. Among employed subjects, the mean (SD) annual days missed from work due to absenteeism were 23.2 (50.4), 32.5 (78.9), and 27.8 (50.9) for the US, France, and Germany, respectively.

The mean (SD) number of comorbid conditions was 4.2 (2.4) in the US study, compared with 3.5 (1.8) in France and 2.4 (1.4) in Germany $(P<0.001)$ (Table 2$)$. The majority of subjects in each study had two or more comorbid conditions

Table I Demographic characteristics

\begin{tabular}{|c|c|c|c|c|}
\hline Characteristic & $\begin{array}{l}\text { US } \\
(n=203)\end{array}$ & $\begin{array}{l}\text { France } \\
(n=70)\end{array}$ & $\begin{array}{l}\text { Germany } \\
(n=169)\end{array}$ & $P$-value \\
\hline Age, years & & & & $0.085^{\mathrm{a}}$ \\
\hline Mean (SD) & $47.9(10.89)$ & $51.2(9.47)$ & $49.2(9.80)$ & \\
\hline Median & 50 & 53.5 & 52 & \\
\hline Range & $19-65$ & $19-65$ & $20-65$ & \\
\hline Gender, n (\%) & & & & $<0.001^{\mathrm{b}}$ \\
\hline Male & II (5.4) & $12(17.1)$ & $34(20.1)$ & \\
\hline Female & $192(94.6)$ & $58(82.9)$ & 135 (79.9) & \\
\hline \multicolumn{3}{|c|}{ Employment status, $\mathbf{n}(\%)^{c}$} & & $<0.00 I^{\mathrm{b}}$ \\
\hline Employed, full-time & $57(28.1)$ & $22(3 \mid .4)$ & $57(33.7)$ & \\
\hline Employed, part-time & $26(12.8)$ & $6(8.6)$ & $17(10.1)$ & \\
\hline Unemployed & $16(7.9)$ & $5(7.1)$ & II (6.5) & \\
\hline Disabled & $55(27.1)$ & $8(11.4)$ & $5(3.0)$ & \\
\hline Retired & $12(5.9)$ & $17(24.3)$ & $16(9.5)$ & \\
\hline Full-time homemaker & $25(12.3)$ & $2(2.9)$ & $28(16.6)$ & \\
\hline Student & $4(2.0)$ & I (I.4) & $0(0.0)$ & \\
\hline Other & $8(3.9)$ & $2(2.9)$ & $21(12.4)$ & \\
\hline
\end{tabular}

Notes: ${ }^{a}$ Kruskal-Wallis test; ${ }^{\text {} P e a r s o n}$ chi-square test; 'percentages for each group may not add up to $100 \%$, due to missing data.

Abbreviation: SD, standard deviation.
Table 2 Comorbid conditions

\begin{tabular}{|c|c|c|c|c|}
\hline & $\begin{array}{l}\text { US } \\
(n=203)\end{array}$ & $\begin{array}{l}\text { France } \\
(\mathrm{n}=70)\end{array}$ & $\begin{array}{l}\text { Germany } \\
(n=169)\end{array}$ & $P$-value ${ }^{\text {a }}$ \\
\hline \multicolumn{4}{|c|}{ Number of comorbid conditions, $\mathbf{n}(\%)$} & $<0.001$ \\
\hline 0 & $13(6.4)$ & $4(5.7)$ & $28(16.6)$ & \\
\hline 1 & $25(12.3)$ & $9(12.9)$ & $49(29.0)$ & \\
\hline 2 & $35(17.2)$ & $13(18.6)$ & $35(20.7)$ & \\
\hline$\geq 3$ & $130(64.0)$ & $44(62.9)$ & $57(33.7)$ & \\
\hline \multirow{2}{*}{\multicolumn{4}{|c|}{$\begin{array}{l}\text { Total number of comorbid conditions among } \\
\text { subjects with at least one comorbid condition }\end{array}$}} & $<0.00 \mathrm{I}^{\mathrm{b}}$ \\
\hline & & & & \\
\hline $\mathrm{n}$ & 190 & 66 & $|4|$ & \\
\hline Mean (SD) & $4.2(2.44)$ & $3.5(1.78)$ & $2.4(1.43)$ & \\
\hline Median & 4 & 3 & 2 & \\
\hline Range & $1-10$ & $\mathrm{I}-8$ & $1-6$ & \\
\hline \multicolumn{4}{|c|}{ Comorbid conditions, $\mathbf{n}(\%)^{\mathrm{b}}$} & $<0.001$ \\
\hline $\begin{array}{l}\text { Sleep disturbance/ } \\
\text { insomnia }\end{array}$ & I $38(68.0)$ & $42(60.0)$ & $79(46.8)$ & $<0.001$ \\
\hline Depressive symptoms & I I 7 (57.6) & $34(48.6)$ & $71(42.0)$ & 0.011 \\
\hline Headache/migraine & $105(5 \mid .7)$ & $25(35.7)$ & $53(31.4)$ & $<0.001$ \\
\hline Anxiety & I0I (49.8) & $54(77.1)$ & $46(27.2)$ & $<0.001$ \\
\hline $\begin{array}{l}\text { Chronic fatigue } \\
\text { syndrome }\end{array}$ & $86(42.4)$ & $37(52.9)$ & $36(21.3)$ & $<0.001$ \\
\hline $\begin{array}{l}\text { Irritable bowel } \\
\text { syndrome }\end{array}$ & $74(36.5)$ & $14(20.0)$ & $23(13.6)$ & $<0.001$ \\
\hline Restless leg syndrome & $58(28.6)$ & I8 (25.7) & $23(13.6)$ & 0.002 \\
\hline Cognitive dysfunction & $55(27.1)$ & $N R$ & $N R$ & NA \\
\hline $\begin{array}{l}\text { Major depressive } \\
\text { disorder }\end{array}$ & $47(23.2)$ & NR & NR & NA \\
\hline Raynaud's syndrome & $15(7.4)$ & $4(5.7)$ & $6(3.6)$ & 0.280 \\
\hline Other & NR & $5(7.1)$ & $6(3.6)$ & 0.228 \\
\hline
\end{tabular}

Notes: ${ }^{\text {PPearson }}$ chi-square test for number of comorbid conditions (categorical representation) and individual comorbid conditions, and Kruskal-Wallis test for number of comorbid conditions (continuous representation); ${ }^{b}$ categories are not mutually exclusive.

Abbreviations: NR, not reported; NA, not assessed.

( $81 \%$ in the US, $82 \%$ in France, and 54\% in Germany). Sleep disturbance was the most common comorbid condition in these studies $(68 \%$ in the US, $60 \%$ in France, and $47 \%$ in Germany; $P<0.001)$. Other common comorbid conditions included depressive symptoms (58\%, 49\%, and $42 \%$ in the US, France, and Germany, respectively), headache/migraine (52\%, 36\%, and $31 \%$ ), anxiety (50\%, 77\%, and $27 \%$ ), and chronic fatigue syndrome $(42 \%, 53 \%$, and $21 \%)$.

In the US study, the mean (SD) time since first reported FM symptoms was 10.7 (8.1) years (range $0-48$ years). The mean (SD) time since first reported FM symptoms was not collected in the European study, but nearly three-quarters of subjects (71\% in France and $72 \%$ in Germany) reported that symptoms had been present for 5 years or less. The mean (SD) time since diagnosis was 6.9 (6.5) years (range 0-48 years) in the US, 2.9 (2.8) years (range 0-16 years) in France, and 4.3 (3.6) years (range 0-22 years) in Germany $(P<0.001)$. US subjects tended to report more severe FM, with a reported mean (SD) FIQ total score 
(scored from 0 to 100) of 63.2 (19.0), and 10\%, 24\%, and $66 \%$ of subjects reporting mild, moderate, and severe FM, respectively (Figure 1). In the European study, the mean (SD) FIQ total score was 54.7 (17.6) in France and 53.4 (20.9) in Germany, with 21\%, 36\%, and 43\% of French subjects and $25 \%, 30 \%$, and $46 \%$ of German subjects reporting mild, moderate, and severe FM, respectively. The greater proportion of patients with severe FM in the US than in France and Germany may be related to the number of comorbid conditions in each country, as US subjects had nearly one more comorbid condition than French subjects, and nearly two more than German subjects.

\section{Health-resource utilization}

Most subjects (92\% in the US, $83 \%$ in France, and 93\% in Germany) were taking at least one prescription medication for FM, and the majority in the US (73\%), France (70\%), and Germany (56\%) were taking two or more. In the US, the highest proportions of subjects were prescribed antidepressants (56\%), analgesics other than anti-inflammatories (51\%), and antiepileptics (36\%). In France, analgesics other than anti-inflammatories (60\%), anti-inflammatories (39\%), antidepressants (34\%), and anxiolytics (30\%) were prescribed most often. In Germany, anti-inflammatories (65\%) were the most often prescribed for FM followed by antidepressants (34\%) and analgesics other than anti-inflammatories (31\%). Similar data were also obtained in a more recent survey of FM patients in Germany. ${ }^{54}$ Nearly one-quarter (22\%) of US subjects reported that their prescription medications were extremely or very effective, compared with $29 \%$ in Germany and $4 \%$ in France $(P<0.001)$ (Table 3$)$. At the same time, $14 \%$ of US subjects reported being extremely satisfied with their prescription medications, compared with $12 \%$ in Germany and $0 \%$ in France $(P=0.039)$.

Subjects in the US had a mean (SD) of 4.2 (4.5) FMrelated physician office visits over the past 3 months (Table 3), corresponding to 16.9 physician office visits per year. Subjects in Europe had a mean (SD) of 4.2 (2.8) FMrelated physician office visits over the past 3 months (2.9 [2.0] and 4.8 [2.9] in France and Germany, respectively), corresponding to 16.9 FM-related physician office visits per year (11.7 in France and 19.1 in Germany). In addition, nearly $21 \%$ of US subjects visited physical therapist or massage therapist offices. In total, US subjects averaged an additional 1.9 (6.0) such visits (range 0-42 visits) over the past 3 months, corresponding to an additional 7.6 FM-related office visits per year. Data on nonmedical office visits were not collected in the European study.

The high HRU rates found in each of the three countries are consistent with other studies that have documented high levels of HRU among FM patients in the US. ${ }^{5,15}$ The high HRU rates for nonphysician office visits in the US are also in agreement with previous studies ${ }^{5}$ and suggest that these data should also be collected in Europe in order to gain a more complete understanding of the costs associated with FM globally.

\section{Estimated total direct annual costs}

The unadjusted mean (SD) annual direct costs (to payer and to subject) for FM in the US were \$7973 (\$7341) per subject,

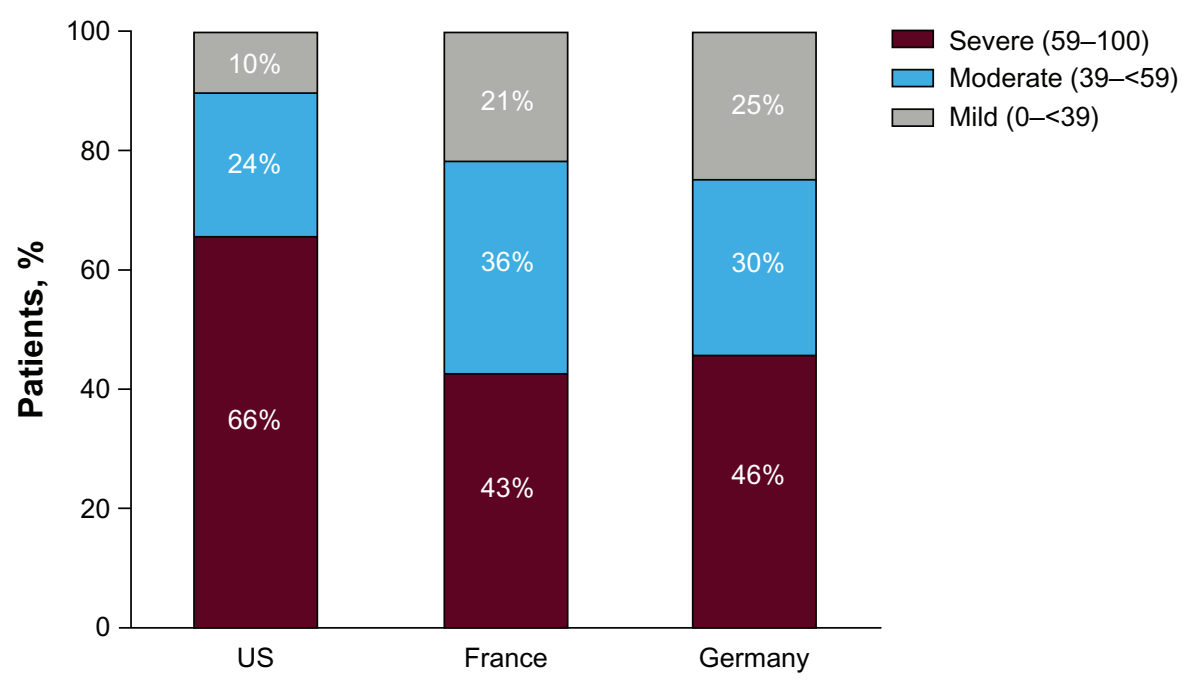

Figure I FIQ severity by country.

Notes: The mean (SD) FIQ total score (scored from 0 to 100) was 63.2 (19.0) in the US, and the pooled mean (SD) FIQ total score for France and Germany was 53.8 (20.0) (54.7 [17.6] in France and 53.4 [20.9] in Germany).

Abbreviations: FIQ, Fibromyalgia Impact Questionnaire; SD, standard deviation. 
Table 3 Physician-reported office visits and subject-reported views on prescribed FM medications

\begin{tabular}{|c|c|c|c|c|}
\hline & US & France & Germany & $P$-value \\
\hline \multicolumn{4}{|c|}{ Number of physician office visits over the past } & $<0.00 I^{\mathrm{a}}$ \\
\hline \multicolumn{5}{|c|}{3 months } \\
\hline $\mathrm{n}$ & 203 & 70 & 169 & \\
\hline Mean (SD) & $4.2(4.47)$ & $2.9(1.98)$ & $4.8(2.92)$ & \\
\hline Median & 3 & 3 & 4 & \\
\hline Range & $\mathrm{I}-33$ & $1-12$ & $1-16$ & \\
\hline \multicolumn{4}{|c|}{ Effectiveness of prescribed FM medication, $n$ (\%) } & $<0.00 I^{b}$ \\
\hline n & 170 & 55 & 130 & \\
\hline Extremely effective & $8(4.7)$ & 0 & $2(1.5)$ & \\
\hline Very effective & $30(17.6)$ & $2(3.6)$ & $36(27.7)$ & \\
\hline Somewhat effective & $79(46.5)$ & $31(56.4)$ & $63(48.5)$ & \\
\hline A little effective & $43(25.3)$ & $21(38.2)$ & $27(20.8)$ & \\
\hline Not at all effective & $10(5.9)$ & I ( I.8) & $2(1.5)$ & \\
\hline \multicolumn{4}{|c|}{ Satisfaction with prescribed FM medication, n (\%) } & $0.039^{b}$ \\
\hline $\mathrm{n}$ & 169 & 55 & 130 & \\
\hline Extremely satisfied & $24(14.2)$ & 0 & $16(12.3)$ & \\
\hline Somewhat satisfied & $56(33.1)$ & $23(41.8)$ & $50(38.5)$ & \\
\hline Neither satisfied & $30(17.8)$ & $15(27.3)$ & $35(26.9)$ & \\
\hline \multicolumn{5}{|l|}{ nor dissatisfied } \\
\hline Somewhat dissatisfied & $44(26.0)$ & $13(23.6)$ & $23(17.7)$ & \\
\hline Extremely dissatisfied & $15(8.9)$ & $4(7.3)$ & $6(4.6)$ & \\
\hline
\end{tabular}

Notes: ${ }^{K}$ Kruskal-Wallis test; ${ }^{\text {PPearson }}$ Chi-square test.

Abbreviations: FM, fibromyalgia; SD, standard deviation.

which were mainly attributable to: prescription medications, \$3419 (\$3667); patient out-of-pocket costs, \$1798 (\$3056); and physician office visits, $\$ 1528$ (\$1953) (Table 4). The mean (SD) annual direct costs per subject for FM were $\$ 924$ (\$862) in France and \$2234 (\$2641) in Germany. The primary drivers of direct costs in the European countries were the same as in the US. Prescription medication costs totaled \$312 (\$430) and \$606 (\$1344), physician office visits totaled \$297 (\$200) and \$564 (\$262), and patient out-of-pocket costs totaled \$223 (\$515) and \$576 (\$1272) in France and Germany, respectively (Table 4).

Results from general linear regression showed that there were significant differences in direct costs for FM per subject across countries. The mean annual adjusted direct costs per subject for FM were significantly higher in the US (\$7087) than in France $(\$ 481, P<0.001)$ and Germany $(\$ 2417$, $P<0.001$ ) (Figure 2). A comparison between European countries showed significantly higher costs in Germany than in France $(P=0.048)$. In this study, the direct healthcare costs in the US were notably lower (by approximately $50 \%$ ) than those reported in previous retrospective studies using claims databases. ${ }^{16,55,56}$ This may be due to this study specifically recording FM-related costs, while estimates from a claims database may also incorporate costs for other conditions.
Adjusted prescription medication costs were nearly 11 times higher in the US (\$3419) than in France (\$312), and nearly six times higher than in Germany $(\$ 606)$. Prescription medication costs were lowest in France, and subjects in France were less likely to consider their FM medication effective and less likely to be satisfied with their medication (Table 3). Some of the differences in medication costs across countries were due to the fact that US subjects had higher utilization rates of prescription FM medications compared with French and German subjects. Notably, there are now three medications approved for use in FM available in the US (pregabalin, duloxetine, and milnacipran), compared with none in Europe. Other contributing factors included differences in prescription drug prices in the US compared with Europe, and differences in the reported use of brand versus generic medications across countries. More accurate data on brand versus generic use were captured in the US study, which may also have contributed.

Adjusted direct costs due to physician office visits were five times higher in the US (\$1528) than in France (\$297), and nearly three times higher than in Germany (\$564), again driven by differences in utilization and also differences in the cost of physician visits between countries. Adjusted patient out-of-pocket costs were also shown to be eight times higher in the US than in France and three times higher than in Germany. These costs were attributable to higher HRU rates, but also may reflect differences in the countries' healthcare and benefits systems, in that US subjects are likely spending more on insurance, coinsurance, and copayments than their European counterparts do for the same services. The US study included more specialist sites and collected data on nonphysician office visits, which are likely to have contributed to higher medical resource use (and associated direct costs).

In addition, there was a shorter elapsed time between emergence of symptoms and diagnosis in the European study compared with the US study. Previous studies in the US and Europe have documented that substantial costs occur prior to a confirmed diagnosis of FM, due to the increased resources necessary to confirm the diagnosis and repeated physician office visits, tests and imaging, specialist care, and drugs. ${ }^{5,19,57}$ This could potentially add significant additional costs to the total cost of treating an FM patient in the US.

\section{Estimated total indirect annual costs}

The unadjusted mean (SD) annual indirect costs per subject for FM attributable to lost productivity due to absenteeism and disability in the US were $\$ 10,697$ (\$20,463), compared 


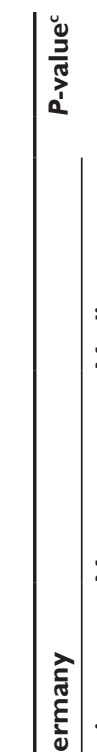

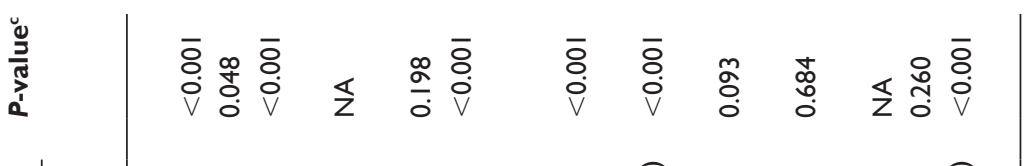

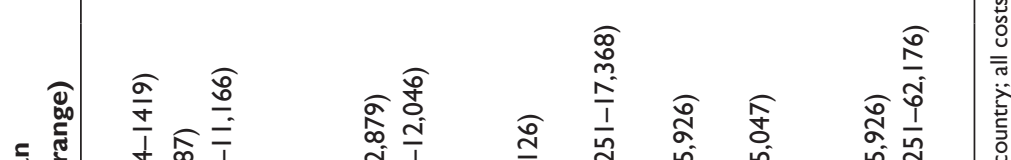

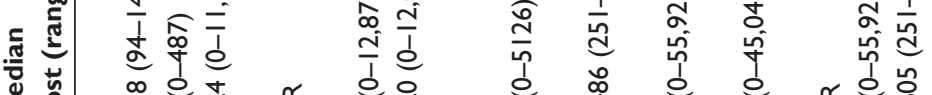

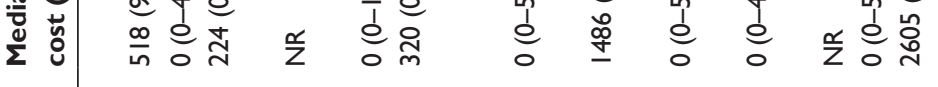

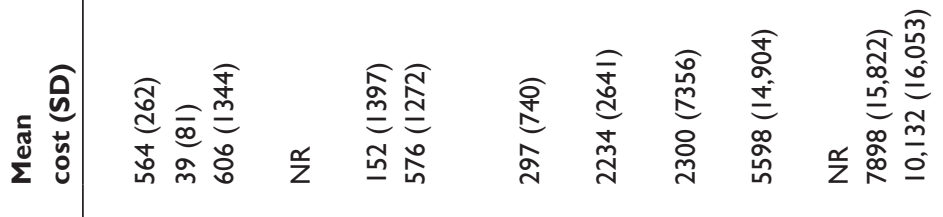

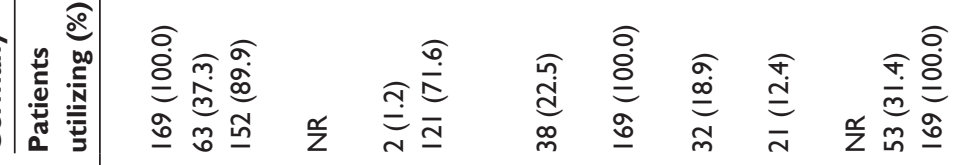

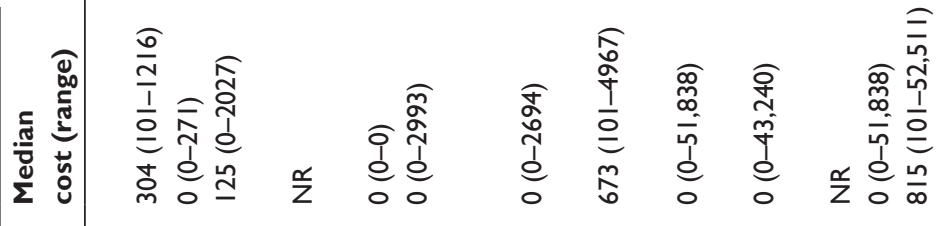

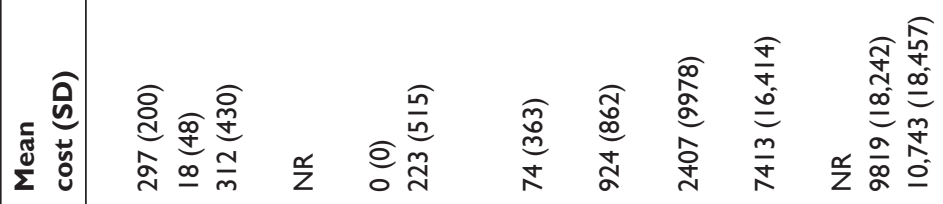

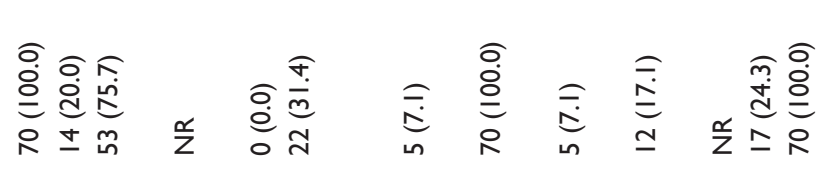

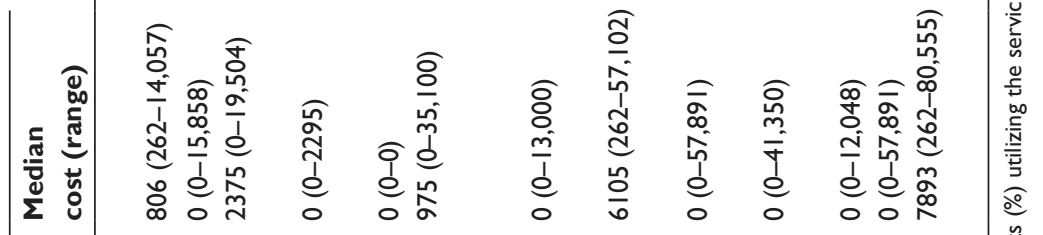

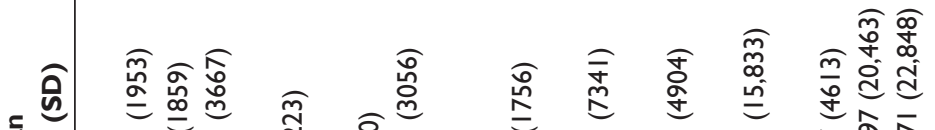

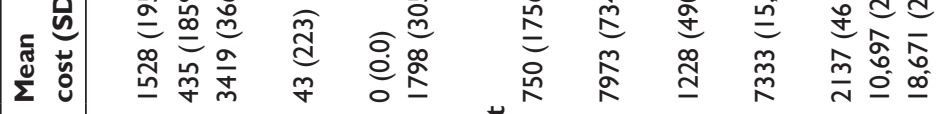

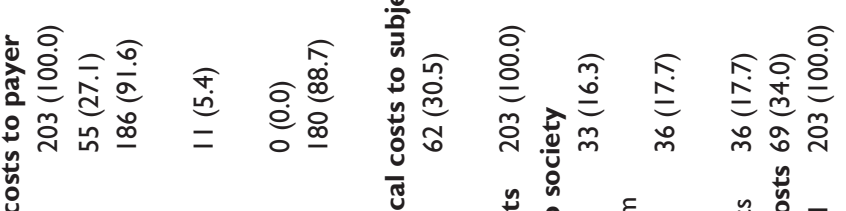

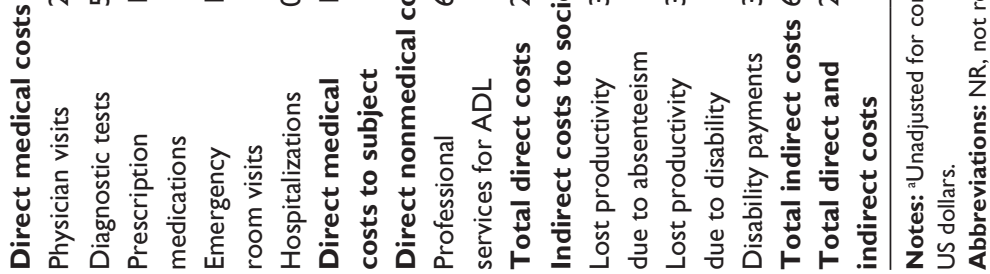




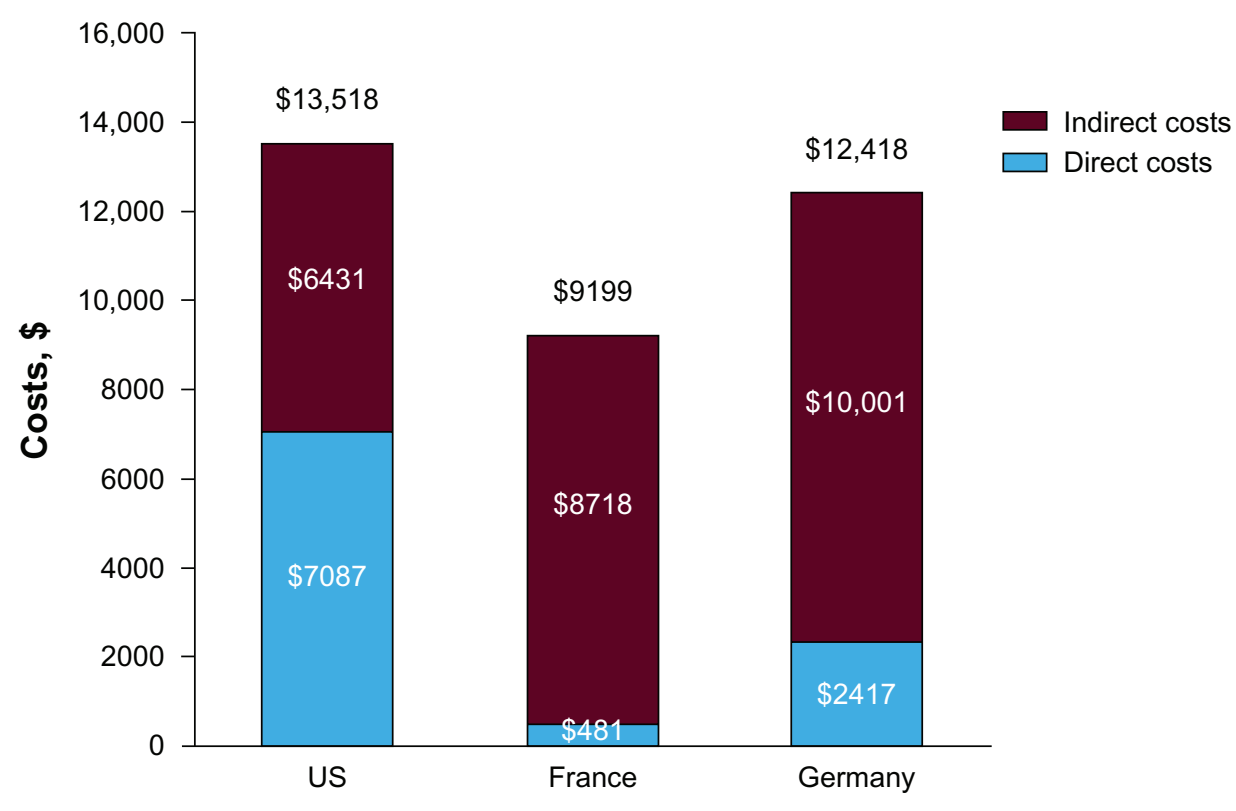

Figure 2 Indirect and direct adjusted costs by country.

Notes: All values are in 2009 US dollars. Costs are adjusted by multivariate regression, controlling for: country, employment status, gender, age, number of comorbid conditions, time since fibromyalgia diagnosis, and FIQ severity level (mild, moderate, or severe).

with $\$ 9819(\$ 18,242)$ in France and $\$ 7898(\$ 15,822)$ in Germany (Table 4). Costs due to absenteeism were lowest in the US, with an unadjusted mean (SD) of \$1228 (\$4904), compared with \$2407 (\$9978) in France and \$2300 (\$7356) in Germany. Lost productivity mean (SD) costs due to disability were lower in Germany (\$5598 [\$14,904]) than in France $(\$ 7413[\$ 16,414])$ and the US (\$7333 [\$15,833]). The US total disability cost included disability payments averaging \$2137 (\$4613) annually per subject.

Results from the multivariate regression showed that numerically adjusted mean annual indirect costs per subject for FM were lowest in the US (\$6431) compared with France (\$8718) and Germany (\$10,001) (Figure 2); however, none of the pair-wise comparisons between countries were significant.

As the French and German indirect costs did not incorporate monthly disability payments, we would have expected them to be closer to the US than they were. The difference between unadjusted and adjusted costs likely reflects the differences in the proportions of severe FM and disabled subjects across the different countries. Among those employed, the average number of days missed from work was not significantly different across countries $(P=0.136)$. While absenteeism and disability accounted for $57 \%$ of total indirect costs in the US, they accounted for $91 \%$ and $78 \%$ of total indirect costs in France and Germany, respectively. Given that additional indirect costs associated with unemployment, reduced work schedule, and caregiver lost productivity have been documented in the US, ${ }^{24}$ it is likely that the total indirect costs due to FM are even higher than those reported in this study.

There were a number of limitations to our analysis. The US and European studies were cross-sectional, requiring a retrospective review of medical records to identify HRU and as such there may have been underreporting of HRU due to incomplete records. For example, visits to other physicians might not have been recorded in the records at the study site or the chart may not have captured services or procedures performed at other facilities. As the studies were performed in the community-based physician office setting, HRU related to hospital care may have been underreported. Actual costs were not determined in this study; direct costs were assigned using a standard algorithm. Actual costs to the payer may be higher or lower. There could have been a recruitment bias in the study, as we enrolled FM subjects seeking care during a routine office visit. We do not have similar objective data for subjects who did not enroll. As noted above, the US study included more specialist sites and collected data on nonphysician office visits, which may have contributed to greater reported HRU in the US study compared with the European study. Medical insurance coverage for subjects in the US study was not recorded. If the larger proportion of subjects were privately insured, then the costs reported here may be an underestimate. Conversely, if the larger proportion of subjects were covered by Medicaid, then the costs may be an overestimate. 


\section{Conclusion}

This study highlights the extent of this burden in the US, France, and Germany, and with the advantage of consistent data-collection methods was able to make a direct comparison of both costs and HRU between these countries. Consistent with previously published studies in the US ${ }^{5,14,15,17}$ and Europe, ${ }^{12,18,57}$ this study showed that FM is associated with substantial direct and indirect costs to payers, patients, and society. Direct costs related to FM were significantly higher in the US compared with France or Germany, despite having similar drivers of total direct costs. Indirect costs proved to be a major component of total patient costs due to FM in all three countries. At the same time, there were notable differences in the use of prescription medications for FM, and their costs, between each country. Despite differences in health-care systems and drivers of costs associated with FM between countries, FM patients' clinical characteristics were generally similar and drove the substantial burden of disease in each country.

\section{Acknowledgments}

The authors would like to thank Don Goldenberg, MD, for guidance and assistance with the analysis and preparation of the manuscript. The authors would also like to acknowledge Rebecca Baik, Meghan Hufstader, PhD, and Kate Anastassopoulos, MS, of Covance Market Access Services Inc, and Joanna Lui, MPH, a research associate with Pfizer Inc at the time of the study, for their support with the analysis and review of the manuscript. Editorial support was provided by Joshua Fink, PhD, of UBC Scientific Solutions, and funded by Pfizer Inc.

\section{Disclosure}

This study was funded by Pfizer Inc. GZ is an employee of Pfizer Inc. At the time of this study, AC was an employee of Pfizer Inc. TK and CS are employees of Covance Market Access Services Inc, who were paid consultants to Pfizer Inc during the conduct of this study and in connection with the development of this manuscript. AW and SP were not compensated for their contribution to this manuscript.

\section{References}

1. Wolfe F, Smythe HA, Yunus MB, et al. The American College of Rheumatology 1990 criteria for the classification of fibromyalgia. Report of the multicenter criteria committee. Arthritis Rheum. 1990;33(2): $160-172$.

2. Arnold LM, Hudson JI, Keck PE, Auchenbach MB, Javaras KN, Hess EV. Comorbidity of fibromyalgia and psychiatric disorders. J Clin Psychiatry. 2006;67(8):1219-1225.
3. Bigatti SM, Hernandez AM, Cronan TA, Rand KL. Sleep disturbances in fibromyalgia syndrome: relationship to pain and depression. Arthritis Rheum. 2008;59(7):961-967.

4. Clauw DJ, Crofford LJ. Chronic widespread pain and fibromyalgia: what we know, and what we need to know. Best Pract Res Clin Rheumatol. 2003;17(4):685-701.

5. White LA, Birnbaum HG, Kaltenboeck A, Tang J, Mallett D, Robinson RL. Employees with fibromyalgia: medical comorbidity, healthcare costs, and work loss. J Occup Environ Med. 2008;50(1):13-24.

6. Wolfe F, Ross K, Anderson J, Russell IJ, Hebert L. The prevalence and characteristics of fibromyalgia in the general population. Arthritis Rheum. 1995;38(1):19-28.

7. Lawrence RC, Felson DT, Helmick CG, et al. Estimates of the prevalence of arthritis and other rheumatic conditions in the United States. Part II. Arthritis Rheum. 2008;58(1):26-35.

8. Branco JC, Bannwarth B, Failde I, et al. Prevalence of fibromyalgia: a survey in five European countries. Semin Arthritis Rheum. 2010;39(6): 448-453.

9. Nasonov EL, Soldatov D, Roué-Le Lay K, Boussetta S, Caubère J, Taïeb C. Prevalence of fibromyalgia: early results in Russia. Ann Rheum Dis. 2008;67 Suppl 2:259:THU0391.

10. Perrot S, Vicaut E, Servant D, Ravaud P. Prevalence of fibromyalgia in France: a multi-step study research combining national screening and clinical confirmation: the DEFI study (Determination of Epidemiology of FIbromyalgia). BMC Musculoskelet Disord. 2011;12: 224.

11. Spaeth M, Roué-Le Lay K, Boussetta S, André E, Caubère J, Taïeb C. Prevalence of fibromyalgia: a large-scale European survey: results in Germany. Ann Rheum Dis. 2008;67 Suppl 2:259:THU0389.

12. Boonen A, van den Heuvel R, van Tubergen A, et al. Large differences in cost of illness and wellbeing between patients with fibromyalgia, chronic low back pain, or ankylosing spondylitis. Ann Rheum Dis. 2005;64(3):396-402.

13. Penrod JR, Bernatsky S, Adam V, Baron M, Dayan N, Dobkin PL. Health services costs and their determinants in women with fibromyalgia. J Rheumatol. 2004;31(7):1391-1398.

14. Robinson RL, Birnbaum HG, Morley MA, Sisitsky T, Greenberg PE, Claxton AJ. Economic cost and epidemiological characteristics of patients with fibromyalgia claims. J Rheumatol. 2003;30(6): $1318-1325$

15. Wolfe F, Anderson J, Harkness D, et al. A prospective, longitudinal, multicenter study of service utilization and costs in fibromyalgia. Arthritis Rheum. 1997;40(9):1560-1570.

16. Gore M, Tai KS, Chandran A, Zlateva G, Leslie D. Clinical characteristics, pharmacotherapy, and healthcare resource use among patients with fibromyalgia newly prescribed pregabalin or tricyclic antidepressants. J Med Econ. 2012;15(1):32-44.

17. Thompson JM, Luedtke CA, Oh TH, et al. Direct medical costs in patients with fibromyalgia: cost of illness and impact of a brief multidisciplinary treatment program. Am J Phys Med Rehabil. 2011;90(1): 40-46.

18. Berger A, Sadosky A, Dukes E, Martin S, Edelsberg J, Oster G. Characteristics and patterns of healthcare utilization of patients with fibromyalgia in general practitioner settings in Germany. Curr Med Res Opin. 2008;24(9):2489-2499.

19. Annemans L, Le Lay K, Taieb C. Societal and patient burden of fibromyalgia syndrome. Pharmacoeconomics. 2009;27(7):547-559.

20. Lamotte M, Maugars Y, Le Lay K, Taieb C. Health economic evaluation of outpatient management of fibromyalgia patients and the costs avoided by diagnosing fibromyalgia in France. Clin Exp Rheumatol. 2010;28(6 Suppl 63):S64-S70.

21. Maugars Y, Annemans L, Roué-Le Lay K, André E, Caubère J, Taïeb C. Fibromyalgia: the avoided cost of the non-diagnosed patient in France. Ann Rheum Dis. 2008;67 Suppl 2:258.

22. Bennett RM, Jones J, Turk DC, Russell IJ, Matallana L. An internet survey of 2,596 people with fibromyalgia. BMC Musculoskelet Disord. 2007;8:27. 
23. Kurtze N, Svebak S. Fatigue and patterns of pain in fibromyalgia: correlations with anxiety, depression and co-morbidity in a female county sample. Br J Med Psychol. 2001;74(Pt 4):523-537.

24. Chandran A, Schaefer C, Ryan K, Baik R, McNett M, Zlateva G. The comparative economic burden of mild, moderate, and severe fibromyalgia: results from a retrospective chart review and cross-sectional survey of working-age US adults. J Manag Care Pharm. 2012;18(6): 415-426.

25. Schaefer C, Chandran A, Hufstader M, et al. The comparative burden of mild, moderate and severe fibromyalgia: results from a cross-sectional survey in the United States. Health Qual Life Outcomes. 2011;9:71.

26. Perrot S, Schaefer C, Knight T, Hufstader M, Chandran AB, Zlateva G. Societal and individual burden of illness among fibromyalgia patients in France: association between disease severity and OMERACT core domains. BMC Musculoskelet Disord. 2012;13:22.

27. Perrot S, Winkelmann A, Dukes E, et al. Characteristics of patients with fibromyalgia in France and Germany. Int J Clin Pract. 2010;64(8): $1100-1108$.

28. Winkelmann A, Perrot S, Schaefer C, et al. Impact of fibromyalgia severity on health economic costs: results from a European cross-sectional study. Appl Health Econ Health Policy. 2011;9(2):125-136.

29. McNett M, Goldenberg D, Schaefer C, et al. Treatment patterns among physician specialties in the management of fibromyalgia: results of a cross-sectional study in the United States. Curr Med Res Opin. 2011;27(3):673-683.

30. Sinclair D, Starz TW, Turk DC. The manual tender point survey. 2005. Available from: http://www.fmaware.org/News2eb58. html?page=NewsArticle\&id=6263. Accessed September 2, 2011.

31. [No authors listed]. EuroQol - a new facility for the measurement of health-related quality of life. Health Policy. 1990;16(3):199-208.

32. Hays RD, Stewart AL. Sleep measures. In: Stewart AL, Ware JE Jr, editors. Measuring Functioning and Well-Being. Durham (NC): Duke University Press; 1992:235-239.

33. Zigmond AS, Snaith RP. The hospital anxiety and depression scale. Acta Psychiatr Scand. 1983;67(6):361-370.

34. Burckhardt CS, Clark SR, Bennett RM. The fibromyalgia impact questionnaire: development and validation. J Rheumatol. 1991;18(5): $728-733$.

35. Offenbaecher M, Waltz M, Schoeps P. Validation of a German version of the Fibromyalgia Impact Questionnaire (FIQ-G). J Rheumatol. 2000;27(8):1984-1988.

36. Perrot S, Dumont D, Guillemin F, Pouchot J, Coste J. Quality of life in women with fibromyalgia syndrome: validation of the QIF, the French version of the fibromyalgia impact questionnaire. $J$ Rheumatol. 2003; 30(5):1054-1059.

37. Belza BL, Henke CJ, Yelin EH, Epstein WV, Gilliss CL. Correlates of fatigue in older adults with rheumatoid arthritis. Nurs Res. 1993;42(2): 93-99.

38. Daut RL, Cleeland CS. The prevalence and severity of pain in cancer. Cancer. 1982;50(9):1913-1918.

39. Bennett RM, Bushmakin AG, Cappelleri JC, Zlateva G, Sadosky AB. Minimal clinically important difference in the fibromyalgia impact questionnaire. J Rheumatol. 2009;36(6):1304-1311.

40. Department of Health and Human Services, Centers for Medicare and Medicaid Services. Medicare physician fee schedule for CY 2009. 42 CFR parts 405 and 409: final rule. Fed Regist. 2008:69725-70237.
41. Department of Health and Human Services, Centers for Medicare and Medicaid Services. 2009 Medicare hospital outpatient prospective payment system. 42 CFR parts 410, 416, and 419: final rule. Fed Regist. 2008:68501-69380.

42. Department of Health and Human Services, Centers for Medicare and Medicaid Services. 2009 Medicare hospital inpatient prospective payment system. 42 CFR: final rule. Fed Regist. 2008:57887-58017.

43. Department of Health and Human Services. Report to the President: Prescription drug coverage, spending, utilization, and prices. Chapter 3. 2000. Available from: http://aspe.hhs.gov/health/reports/drugstudy/ chap03.htm. Accessed February 27, 2012.

44. Thomson Reuters. ReadyPrice [CD-ROM]. Version 2009:4. New York: Thomson Reuters; 2009.

45. National Bureau of Labor Statistics. Occupational earnings tables: United States, Dec 2006-Jan 2008. 2008. Available from: http://www. bls.gov/ncs/ncswage2007.htm\#Wage_Tables. Accessed April 22, 2009.

46. Social Security Administration. Fast facts and figures about social security, 2008. Available from: https://www.socialsecurity.gov/policy/ docs/chartbooks/fast_facts/2008/fast_facts08.html. Accessed April 22, 2009.

47. French National Authority for Health. Common classification for medical services 2008. Available from: http://www.ccam.sante.fr. Accessed February 26, 2013. French.

48. National Association of Sickness Fund Physicians. Uniform rating scale for medical services. 2008. Available from: http://www.kbv. de/ebm2000plus/EBMGesamt.htm. Accessed September 1, 2008. German.

49. Technical Agency for Information on Hospitalization. Program of medicalization of information systems. 2008. Available from: https:// www.epmsi.atih.sante.fr. Accessed April 1, 2008.

50. German Diagnosis-Related Group [homepage on the Internet]. Available from: http://drg.uni-muenster.de. Accessed April 1, 2008. German.

51. Thériaque [homepage on the Internet]. Available from: http://www. theriaque.org. Accessed April 1, 2008. French.

52. Rote List [homepage on the Internet]. Available from: http://www.roteliste.de. Accessed April 1, 2008. German.

53. The Organisation for Economic Co-operation and Development (OECD). PPP benchmark results 2008. 2011. Available from: http:// www.oecd-ilibrary.org/content/data/data-00534-en. Accessed April 1, 2008.

54. Häuser W, Jung E, Erbslöh-Möller B, et al. German fibromyalgia consumer reports - a cross-sectional survey. BMC Musculoskelet Disord. 2012;13:74.

55. Gore M, Tai KS, Chandran A, Zlateva G, Leslie D. Clinical comorbidities, treatment patterns, and healthcare costs among patients with fibromyalgia newly prescribed pregabalin or duloxetine in usual care. J Med Econ. 2012;15(1):19-31.

56. Zhao Y, Sun P, Watson P, Mitchell B, Swindle R. Comparison of medication adherence and healthcare costs between duloxetine and pregabalin initiators among patients with fibromyalgia. Pain Pract. 2011;11(3):204-216.

57. Hughes G, Martinez C, Myon E, Taieb C, Wessely S. The impact of a diagnosis of fibromyalgia on health care resource use by primary care patients in the UK: an observational study based on clinical practice. Arthritis Rheum. 2006;54(1):177-183.
ClinicoEconomics and Outcomes Research

\section{Publish your work in this journal}

ClinicoEconomics \& Outcomes Research is an international, peerreviewed open-access journal focusing on Health Technology Assessment, Pharmacoeconomics and Outcomes Research in the areas of diagnosis, medical devices, and clinical, surgical and pharmacological intervention. The economic impact of health policy and health systems

\section{Dovepress}

organization also constitute important areas of coverage. The manuscript management system is completely online and includes a very quick and fair peer-review system, which is all easy to use. Visit http://www.dovepress.com/testimonials.php to read real quotes from published authors. 